\title{
Research on Discretization PI Control Technology of Single-Phase Grid-Connected Inverter with LCL Filter
}

\author{
Jianke Li, ${ }^{1}$ Jinquan Wang, ${ }^{1}$ Ye $\mathrm{Xu},{ }^{1}{ }^{J i a n t i n g ~} \mathrm{Li}^{2}{ }^{2}$ Jingjing Chen, ${ }^{1}$ \\ Pengfei Hou, ${ }^{1}$ and Shuhua Qian ${ }^{1}$ \\ ${ }^{1}$ College of Defense Engineering, PLA University of Science and Technology, Nanjing 210007, China \\ ${ }^{2}$ Department of Electrical Engineering, Eindhoven University of Technology, 5600 MB Eindhoven, The Netherlands
}

Correspondence should be addressed to Jianke Li; 511746569@qq.com

Received 1 June 2014; Revised 10 August 2014; Accepted 15 August 2014; Published 25 September 2014

Academic Editor: Victor Sreeram

Copyright (C) 2014 Jianke Li et al. This is an open access article distributed under the Creative Commons Attribution License, which permits unrestricted use, distribution, and reproduction in any medium, provided the original work is properly cited.

Compared with L-type filter, LCL-type filter is more suitable for high-power low-switching frequency applications with reducing the inductance, improving dynamic performance. However, the parameter design for the LCL filter is more complex due to the influence of the controller response performance of the converter. If the harmonic current around switching frequency can be fully suppressed, it is possible for inverter to decrease the total inductance as well as the size and the cost. In this paper, the model of the LCL filter is analyzed and numerical algorithms are adopted to analyze the stability of the closed-loop control system and stable regions are deduced with different parameters of LCL filter. Then, the minimum sampling frequencies are deduced with different conditions. Simulation and experimental results are provided to validate the research on the generating mechanism for the unstable region of sampling frequency.

\section{Introduction}

Three types of filter, such as L-type, LC-type, and LCLtype, are widely used in grid-connected inverter. Due to the limit of switching frequency, the filter inductance of Ltype grid-connected inverter cannot effectively suppress the harmonic voltage of PWM switching frequency, resulting in grid current with large harmonic current around switching frequency, which should be suppressed by larger filter inductance [1-4]. However, larger filter inductance will cause too large equipment volume and high cost and affect dynamic performance of grid-connected control [5]. Therefore, the inductance-capacitance-inductance (LCL) filter is designed to replace the conventional filter $[6,7]$. In order to improve the attenuation rate of harmonic current around switching frequency, LCL filter is adopted to suppress harmonic voltage around switching frequency as well [8]. However, LCL filter brings new problems, such as the scope of application of LCL filter and the impact on control characteristics caused by LCL filter resonance.

In order to research the stability of inverter with LCL filter, it is important to use simulation models which are sufficiently detailed to realistically represent their real world physical system behaviors. A detailed power inverter model developed within the DIgSILENT power network simulation package, which can reflect the inverter's real dynamic response to transient events, is presented in [9]. A new modeling approach for inverter-dominated microgrids using dynamic phasor is presented. The proposed dynamic phasor model is able to predict accurately the stability margins of the system, while the conventional reduced-order small-signal model fails [10]. In order to predict the dynamic behaviors of inverter, new small-signal $z$-domain models are deduced for digitally controlled grid-connected inverters with converter current control scheme and converter current plus grid current control scheme [11]. The proposed methods allow direct design for controllers in $z$-domain. The simulation results show that the proposed $z$-domain models are more effective in predicting instabilities. As to control method, a PI controller with self-tuning parameter based on fuzzy inferring is proposed [12]. This controller is capable of automatically adjusting two parameters (P and I) of PI controller.

For an LCL filter based single-phase grid-connected fullbridge inverter system, it is possible to decrease the total 


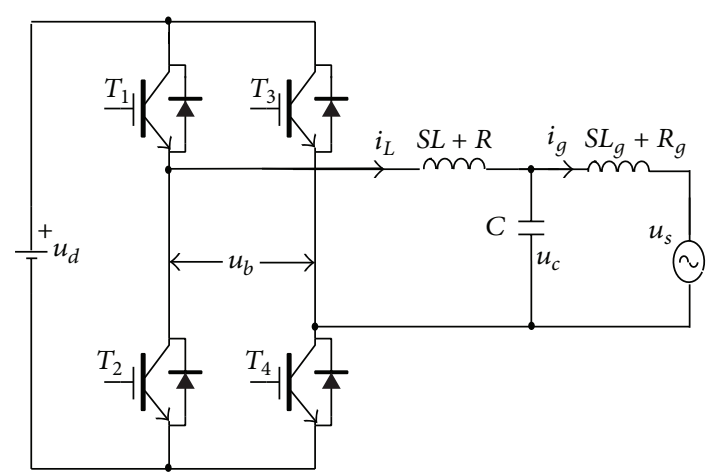

FIGURE 1: Schematic of LCL based grid-connected inverter.

inductance as well as the size and the cost, if the harmonic current around switching frequency can be fully suppressed. LCL filters resonance may lead to the instability of the control system. In order to address this issue, passive damping and active damping have been presented to improve system stability [13-15]. In order to cope with the grid inductance variations, a simple tuning procedure for the notch filter is proposed to estimate the resonance frequency by means of Fourier analysis. The Goertzel algorithm, instead of the FFT, is used to reduce the calculation and memory requirements. Thus, the proposed self-commissioning notch filter increases and consumes little computational resources [16]. Improved passive damping which includes double loop control and makes the system less loss and more stable is proposed [17]. An active damping strategy with harmonics compensation which can alleviate the harmonics around the resonance frequency caused by the LCL filters is proposed in [18]. However, whether LCL filter can effectively suppress the harmonic current with different switching frequencies is not deeply analyzed [19].

Since stability margin of grid current feedback control is small, double closed-loop control, capacitor current feedback inner loop, and grid current feedback outer loop are adopted to increase the stability margin of the system [20]. The inverter side inductance current feedback, which is inner inductance current feedback, is proposed in [8], and they found that the stability margin using this current feedback is larger than current closed-loop control. Besides, the inner inductance current feedback with advantages of simple control algorithm and less feedback parameters has already been applied in [21-23]. In order to enhance the tracking characteristics of grid current, reference current feed forward control is presented. However, whether inner inductor current feedback control can meet grid current tracking features alone is not discussed [8].

This paper will analyze mathematical model of the LCL filter and deeply analyze the stability of inner inductance current control system.

\section{Mathematical Model of Filter}

Figure 1 shows the schematic of single-phase full-bridge PWM inverter with LCL filter. $T_{1}, T_{2}, T_{3}$, and $T_{4}$ are power MOSFETs [24]. $L$ and $R$ are the inner inductance and parasitic

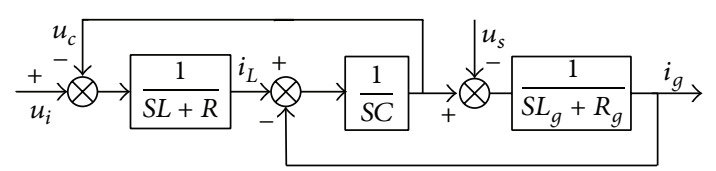

FIGURE 2: The transfer function block diagram of LCL filter.

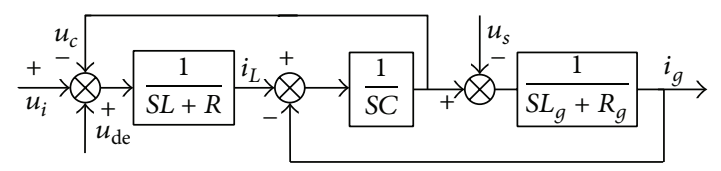

FIGURE 3: The transfer function block diagram of the LCL filter with dead zone effect.

resistance. $L_{g}$ and $R_{g}$ are the grid-side inductance and parasitic resistance. $u_{d}$ and $u_{b}$ are the DC bus voltage and the inverter output voltage, respectively. $u_{s}$ and $u_{c}$ are the grid voltage and capacity voltage, respectively. $i_{L}$ and $i_{g}$ are the inner inductance current and grid current, respectively. The PWM inverter can be equivalent to proportion enlargement link $K$ which is generally normalized to 1 [25]. And the voltage $u_{b}$ between the two bridges can be substituted by reference wave voltage $u_{i}$ (Figure 2).

The electrical relationship of the schematic can be described as follows:

$$
\left[\begin{array}{l}
\dot{i}_{L} \\
\dot{u}_{c} \\
i_{g}
\end{array}\right]=A\left[\begin{array}{l}
i_{L} \\
u_{c} \\
i_{g}
\end{array}\right]+B\left[\begin{array}{l}
u_{i} \\
u_{s}
\end{array}\right],
$$

where

$$
A=\left[\begin{array}{ccc}
-\frac{R}{L} & -\frac{1}{L} & 0 \\
\frac{1}{C} & 0 & -\frac{1}{C} \\
0 & \frac{1}{L_{g}} & -\frac{R_{g}}{L_{g}}
\end{array}\right], \quad B=\left[\begin{array}{cc}
\frac{1}{L} & 0 \\
0 & 0 \\
0 & -\frac{1}{L_{g}}
\end{array}\right] .
$$

The transfer function of LCL filter which can be derived from formula (1) and Figure 1 is shown in Figure 2.

The dead zone effect can be equal to dead zone equivalent voltage source $u_{\mathrm{de}}$; the transfer function block diagram and state equation are shown in Figure 3 and formula (3), respectively. Consider

$$
\left[\begin{array}{c}
\dot{i}_{L} \\
\dot{u}_{c} \\
\dot{i}_{g}
\end{array}\right]=A\left[\begin{array}{c}
i_{L} \\
u_{c} \\
i_{g}
\end{array}\right]+B\left[\begin{array}{c}
u_{i} \\
u_{s} \\
u_{\mathrm{de}}
\end{array}\right],
$$

where

$$
A=\left[\begin{array}{ccc}
-\frac{R}{L} & -\frac{1}{L} & 0 \\
\frac{1}{C} & 0 & -\frac{1}{C} \\
0 & \frac{1}{L_{g}} & -\frac{R_{g}}{L_{g}}
\end{array}\right], \quad B=\left[\begin{array}{ccc}
\frac{1}{L} & 0 & \frac{1}{L} \\
0 & 0 & 0 \\
0 & -\frac{1}{L_{g}} & 0
\end{array}\right] .
$$




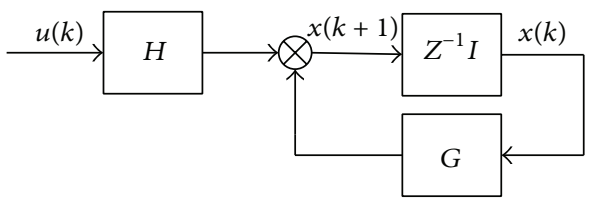

FIgURE 4: The discretization transfer function block diagram of LCL filter.

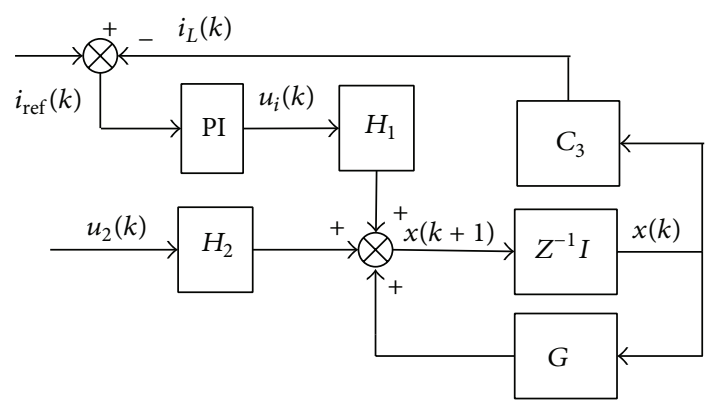

FIgURE 5: The discrete domain block diagram.

The continuous domain transfer functions of the inner inductor current and the grid current are derived from formula (3) as shown below:

$$
\begin{aligned}
& I_{L}(S)=\frac{A(S)}{D(S)}\left(U_{i}(S)+U_{\mathrm{de}}(S)\right)-\frac{1}{D(S)} U_{s}(S), \\
& I_{g}(S)=\frac{1}{D(S)}\left(U_{i}(S)+U_{\mathrm{de}}(S)\right)-\frac{A(S)}{D(S)} U_{s}(S),
\end{aligned}
$$

where

$$
\begin{aligned}
A(S)= & L_{g} C S^{2}+R_{g} C S+1 \\
D(S)= & L L_{g} C S^{3}+\left(L_{g} R+L R_{g}\right) C S^{2} \\
& +\left(R R_{g} C+L+L_{g}\right) S+R+R_{g} .
\end{aligned}
$$

The output voltage of inverter keeps a constant value $u_{i}(k T)$ in $k$ th sampling period $T$, until the next sampling time $(k+1)$; the output voltage becomes $u_{i}((k+1) T)$. The discretization transfer function is shown below:

$$
\begin{aligned}
x(k+1) & =G x(k)+H u(k), \\
y(k) & =i_{g}(k), \\
G & =e^{-A T}, \quad H=A^{-1}\left(1-e^{-A T}\right) B, \\
x(k) & =\left[\begin{array}{c}
i_{L}(k) \\
u_{c}(k) \\
i_{g}(k)
\end{array}\right], \quad u(k)=\left[\begin{array}{c}
u_{i}(k) \\
u_{s}(k) \\
u_{\mathrm{de}}(k)
\end{array}\right] .
\end{aligned}
$$

The block diagram of grid-connected inverter with LCL filter is shown in Figure 4.

\section{Discretization PI Control Technology}

The discrete domain block diagram of PI control technology can be obtained from Figure 4, as shown in Figure 5.
TABLE 1: Six group filters.

\begin{tabular}{lccccc}
\hline Group & $L / \mathrm{mH}$ & $L_{g} / \mathrm{mH}$ & $C / \mathrm{uF}$ & $R / \mathrm{m} \Omega$ & $R_{g} / \mathrm{m} \Omega$ \\
\hline 1st & 1 & 1 & 4.7 & 10 & 10 \\
2nd & 1.5 & 0.5 & 6.3 & 5 & 15 \\
3rd & 0.5 & 1.5 & 6.3 & 5 & 15 \\
4th & 0.5 & 0.5 & 9.4 & 5 & 15 \\
5th & 0.75 & 0.25 & 12.6 & 7.5 & 2.5 \\
6th & 0.25 & 0.75 & 12.6 & 2.5 & 7.5 \\
\hline
\end{tabular}

The state space equation of PI control system can be obtained as shown below [26]:

$$
\begin{gathered}
X(k+1)=G_{I} X(k)+H_{1 I} i_{\mathrm{ref}}(k)+H_{2 I} u_{2}(k), \\
Y(k)=C_{1 I} X(k), \\
C_{1 I}=\left[\begin{array}{llll}
0 & 0 & 1 & 0
\end{array}\right],
\end{gathered}
$$

$$
\begin{aligned}
& G_{I}=\left[\begin{array}{cc}
G-\left(K_{p}+K_{I}\right) H_{1} C_{3} & H_{1} \\
-K_{I} C_{3} & 1
\end{array}\right], \quad X(k)=\left[\begin{array}{c}
i_{L}(k) \\
u_{c}(k) \\
i_{g}(k) \\
e_{I}(k)
\end{array}\right] \text {, } \\
& H_{1 I}=\left[\begin{array}{c}
\left(K_{p}+K_{I}\right) H_{1} \\
K_{I}
\end{array}\right], \quad H_{2 I}=\left[\begin{array}{c}
H_{2} \\
0
\end{array}\right] \text {. }
\end{aligned}
$$

In order to analyze the stability of closed-loop control system, numerical algorithm is adopted to describe the region where the root is less than 1 . Six filters with various ratios between inner inductance and outside inductance are selected to evaluate the range of stability domain, as shown in Table 1 .

In these six group filters, the resonant frequency $f_{\text {res }}$ is $3.3 \mathrm{kHz}$ and closed-loop damping ratio coefficient $\xi$ of closedloop control system is 0.707 . The curves of closed-loop root critical frequency $f_{n \max }$ with different sampling frequencies can be obtained according to formula (9), as shown in Figure 6:

$$
0<f n<\frac{\sqrt{1+\xi^{2}}-\xi}{\pi T}=\frac{\sqrt{1+\xi^{2}}-\xi}{\pi} f_{s}=f_{n \max } .
$$

As shown in Figure 6, the closed-loop root critical frequency $f_{n \max }$ almost equals zero in several groups. These regions are defined as the unstable region of sampling frequency. From Figure 6, the unstable region of sampling frequency (ribbon) is present in all these filters. The curves of closed-loop root critical frequency $f_{n \text { max }}$, respectively, overlap between group 1 and group 4, group 2 and group 5 , and group 3 and group 6 , which indicates that the ranges of closed-loop root frequency are identical when the resonance frequencies are the same and the ratios between inner inductance and outside inductance are the same.

The upper and lower frequency can be obtained from Figure 6, as shown in Table 2. The ratios $K_{\text {ufs }}$ between upper frequency and resonant frequency and the ratios $K_{\text {ufs }}$ between lower frequency and resonant frequency are listed in Table 2 as well. 
TABLE 2: The unstable region under different parameters.

\begin{tabular}{|c|c|c|c|c|c|c|c|c|}
\hline & \multicolumn{2}{|c|}{ Unstable region $1 / \mathrm{Hz}$} & \multicolumn{2}{|c|}{ Unstable region $2 / \mathrm{Hz}$} & \multicolumn{2}{|c|}{ Unstable region $3 / \mathrm{Hz}$} & \multicolumn{2}{|c|}{ Unstable region $4 / \mathrm{Hz}$} \\
\hline & Upper & Lower & Upper & Lower & Upper & Lower & Upper & Lower \\
\hline 1 st & 6600 & 3450 & 2175 & 1720 & 1310 & 1140 & 940 & 855 \\
\hline 2nd & 6600 & 3500 & 2175 & 1750 & 1310 & 1160 & 940 & 855 \\
\hline $3 \mathrm{rd}$ & 6600 & 3350 & 2175 & 1680 & 1310 & 1120 & 940 & 840 \\
\hline 4 th & 6600 & 3450 & 2175 & 1720 & 1310 & 1140 & 940 & 855 \\
\hline 5 th & 6600 & 3500 & 2175 & 1750 & 1310 & 1160 & 940 & 855 \\
\hline 6 th & 6600 & 3350 & 2175 & 1680 & 1310 & 1120 & 940 & 840 \\
\hline$K_{\mathrm{ufs}}$ & $2 / 1$ & $2 / 2$ & $2 / 3$ & $2 / 4$ & $2 / 5$ & $2 / 6$ & $2 / 7$ & $2 / 8$ \\
\hline
\end{tabular}

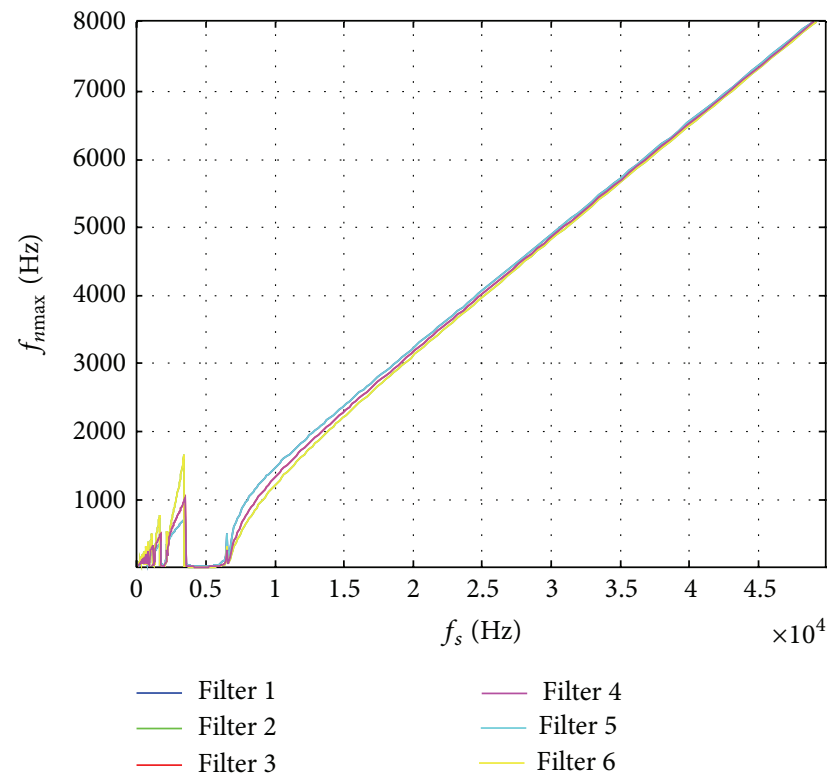

FIGURE 6: Stability domain of filters.

From Table 2, the unstable region can be described below:

$$
\frac{2 f_{\text {res }}}{2 n}<f_{s} \leq \frac{2 f_{\text {res }}}{2 n-1}, \quad n \in N .
$$

In order to verify whether the stability region satisfies formula (10) with different damping ratio coefficients, a group parameter, $L=1 \mathrm{mH}, L_{g}=1 \mathrm{mH}, C=4.7 \mathrm{uF}, R=10 \mathrm{~m} \Omega$, and $R_{g}=10 \mathrm{~m} \Omega$, is selected. The curves of closed-loop root critical frequency $f_{n \text { max }}$ are drawn in Figure 7 when the damping ratio coefficient equals $0,0.2,0.4,0.6,0.8,1.0$, and 1.2 , respectively.

As shown in Figure 7, the frequency ranges of unstable region all satisfy formula (10) with different damping ratio coefficients except when $\xi$ is 0 . The ranges of closed-loop root frequency will gradually increase when the sampling frequency is twice as high as the resonant frequency. What is more, the range of closed-loop root frequency will be consistent with discrete PI control of $L$-type filter when the sampling frequency is three times as high as the resonant frequency.

In accordance with quantitative requirements of closedloop root frequency of grid-connected standard, taking into

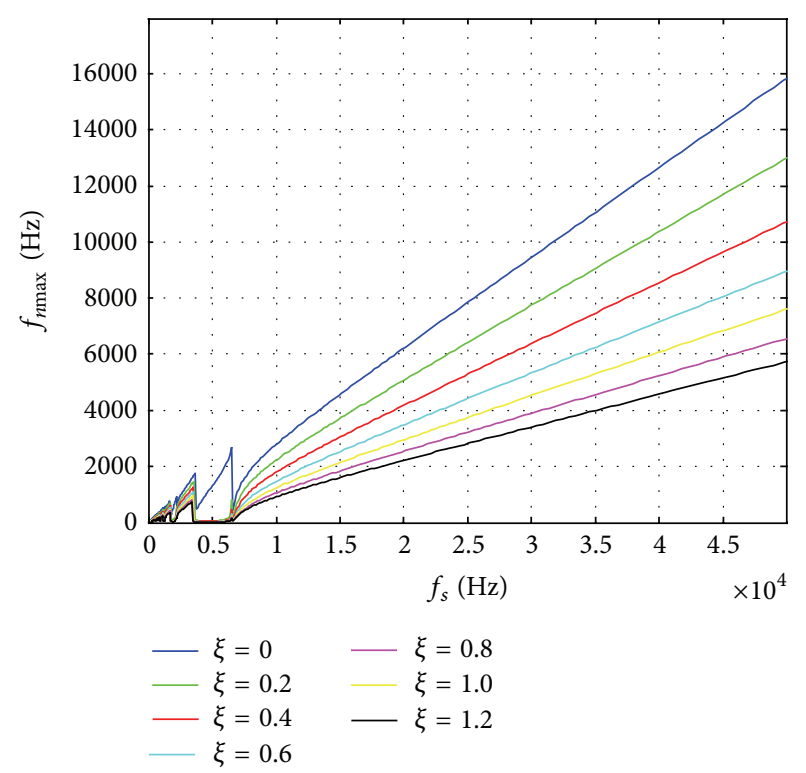

FIGURE 7: Closed-loop root critical frequency $f_{n \max }$ with different damping ratio coefficients.

account the stability margin, according to the method of the minimum sampling frequency, the conclusion can be deduced: the sampling frequency should be greater than $9.68 \mathrm{kHz}$ without the grid voltage feed-forward to satisfy the grid-connected standard indicators, while the sampling frequency should be greater than $3.9 \mathrm{kHz}$ with the grid voltage feed-forward.

\section{Mechanism Research for the Unstable Region of Sampling Frequency}

For the same LCL filter with resonant frequency $f_{\text {res, }}$, we can know from previous sections that a sampling frequency unstable region exists when the filters are controlled by PI method and this area meets formula (10) and has no relation with the closed-loop damping ratio. It is shown that the unstable strip area is related to the discretization of control object. It will be analyzed as follows according to the discretization process of control object.

The discretization process of control objects is mainly manifested in the transfer matrix $G$ of control object, and the 


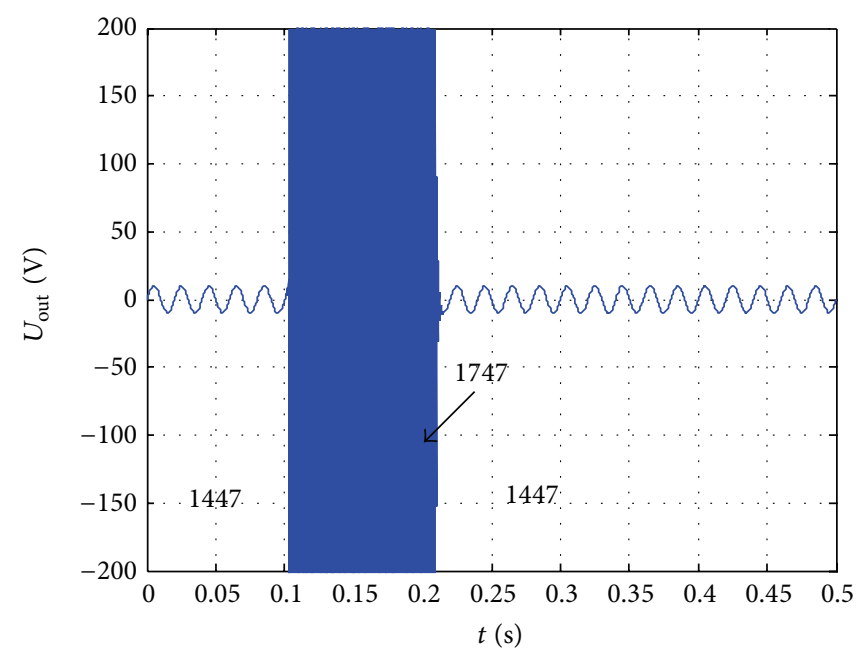

(a) Without limit of output voltage

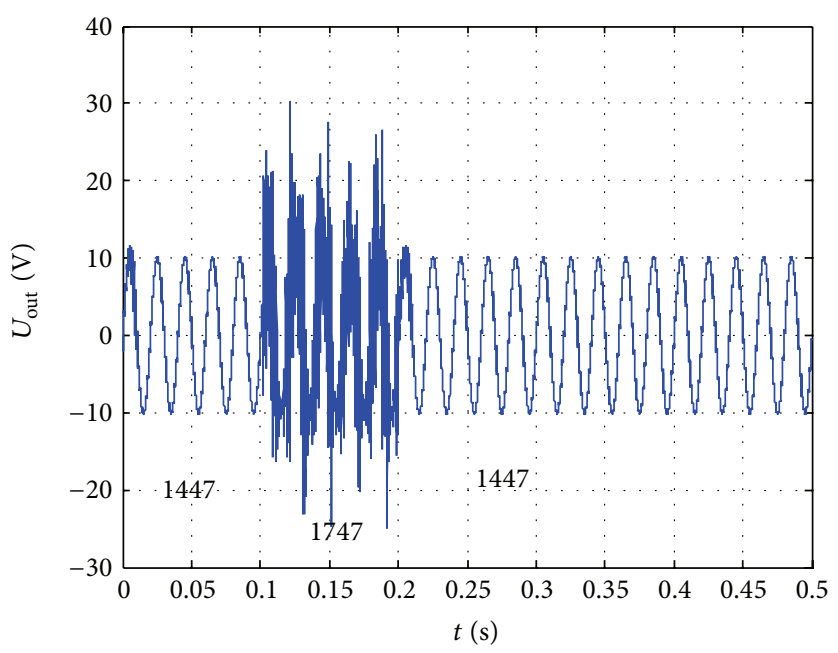

(c) Output voltage with PWM waveform of bipolar modulation

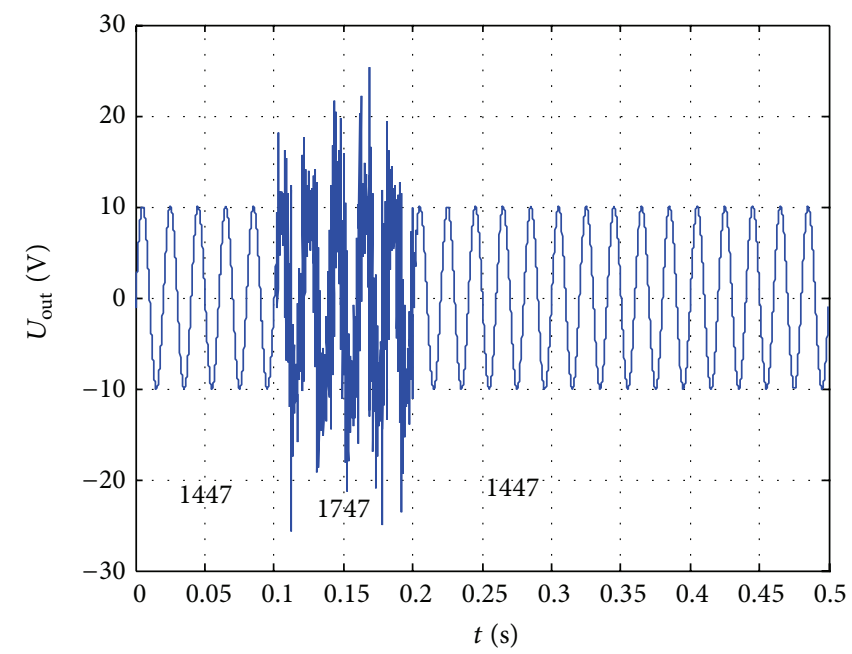

(b) $380 \mathrm{~V}$ limiter of output voltage

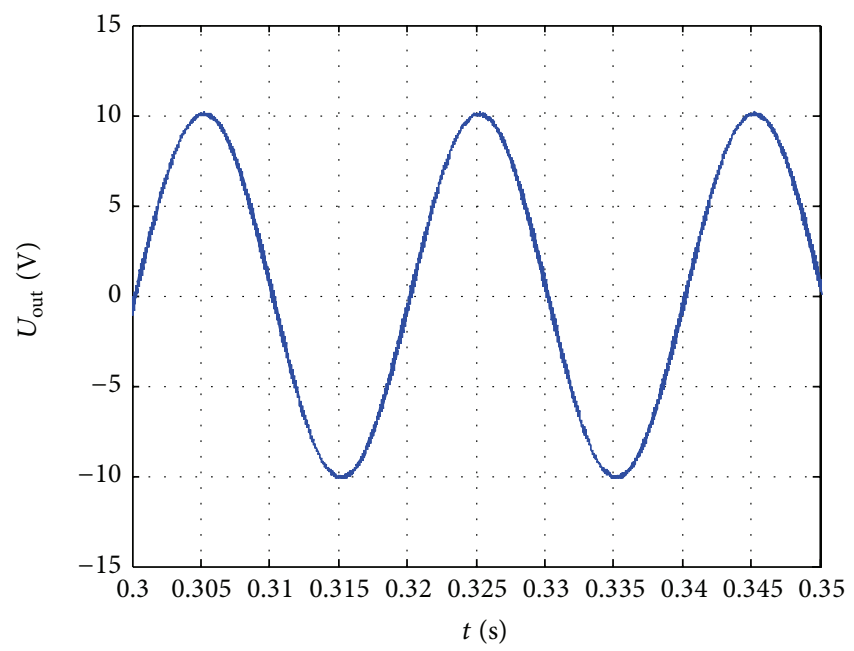

(d) Steady-state waveform zoom of (c)

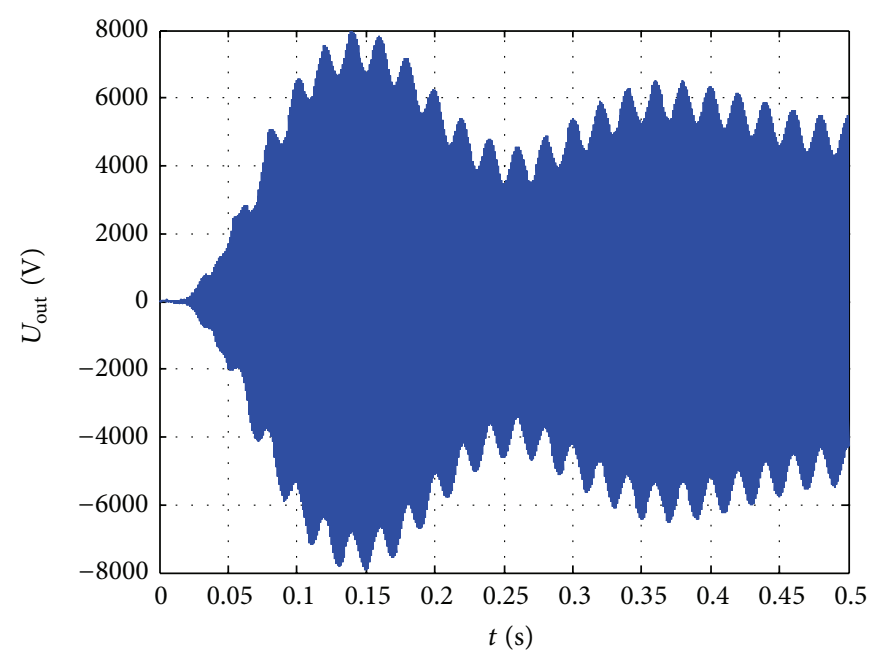

(e) Output voltage with sampling frequency within unstable region

FIGURE 8: The simulation results. 
transfer matrix $H$ is related to input signal; the relationship between matrix functions $G$ and $H$ is represented below:

$$
G=e^{-A T}, \quad H=A^{-1}\left(1-e^{-A T}\right) B,
$$

where

$$
A=\left[\begin{array}{ccc}
-\frac{R}{L} & -\frac{1}{L} & 0 \\
\frac{1}{C} & 0 & -\frac{1}{C} \\
0 & \frac{1}{L_{g}} & -\frac{R_{g}}{L_{g}}
\end{array}\right], \quad B=\left[\begin{array}{ccc}
\frac{1}{L} & 0 & \frac{1}{L} \\
0 & 0 & 0 \\
0 & -\frac{1}{L_{g}} & 0
\end{array}\right] .
$$

The characteristics root of matrix $A$ can be represented by formula (13); since the parasitic resistance of the internal and external inductance is too small, the influence of parasitic resistance can be ignored; the parameters of $a, b$, and $c$ in formula (13) are shown in formula (14):

$$
\begin{aligned}
& \lambda_{1}=a+b i, \\
& \lambda_{2}=a-b i \text {, } \\
& \lambda_{3}=c \text {, } \\
& a=c=0, \quad b=\sqrt{\frac{L+L_{g}}{L L_{g} C}}=2 \pi f_{\text {res }}
\end{aligned}
$$

The coefficient relations of minimum polynomial of the transfer matrix $G$ are described in formula (15) and the coefficient expressions of minimum polynomial are shown in formula (16):

$$
\begin{aligned}
& d_{0}+2 \pi f_{\mathrm{res}} d_{1}-4 \pi^{2} f_{\mathrm{res}}^{2} d_{2}=e^{-2 \pi f_{\mathrm{res}} T i}, \\
& d_{0}-2 \pi f_{\mathrm{res}} d_{1} i-4 \pi^{2} f_{\mathrm{res}}^{2} d_{2}=e^{2 \pi f_{\mathrm{res}} T i}, \\
& d_{0}=e^{0} \\
& d_{0}=1 \\
& d_{1}=-\frac{\sin \left(2 \pi f_{\mathrm{res}} T\right)}{2 \pi f_{\mathrm{res}}} \\
& d_{2}=\frac{1-\cos \left(2 \pi f_{\mathrm{res}} T\right)}{4 \pi^{2} f_{\mathrm{res}}^{2}} .
\end{aligned}
$$

The expression of matrix functions $G$ and $H$ can be deduced as shown below:

$$
\begin{aligned}
G=I & -\frac{\sin \left(2 \pi f_{\text {res }} T\right)}{2 \pi f_{\text {res }}} A+\frac{1-\cos \left(2 \pi f_{\text {res }} T\right)}{4 \pi^{2} f_{\text {res }}^{2}} A^{2}, \\
H= & \left.\frac{\sin \left(2 \pi f_{\text {res }} T\right)}{2 \pi f_{\text {res }}} I-\frac{1-\cos \left(2 \pi f_{\text {res }} T\right)}{4 \pi^{2} f_{\text {res }}^{2}} A\right) \\
& \times\left[\begin{array}{ccc}
\frac{1}{L} & 0 & \frac{1}{L} \\
0 & 0 & 0 \\
0 & -\frac{1}{L_{g}} & 0
\end{array}\right] .
\end{aligned}
$$

From formula (17), the relationship matrix between output voltage $u_{i}$ of inverter and state quantity of LCL filter parameters can be inferred as shown below:

$$
H_{1}=\left[\begin{array}{c}
\frac{\sin \left(2 \pi f_{\mathrm{res}} T\right)}{2 \pi f_{\mathrm{res}} L} \\
\frac{1-\cos \left(2 \pi f_{\mathrm{res}} T\right)}{4 \pi^{2} f_{\mathrm{res}}^{2} L C} \\
0
\end{array}\right] .
$$

From formula (18), the output voltage of inverter is positive and the inner inductance current increases when $\sin \left(2 \pi f_{\text {res }} T\right)$ is greater than zero. When $\sin \left(2 \pi f_{\text {res }} T\right)$ is less than zero, the output voltage of inverter is positive, but the inner inductance current decreases. However, when designing the inner inductance current closed-loop control, positive output voltage and the enlargement of inner inductance current are considered. Therefore, the system feedback turns into positive from negative, which results in unstable system when $\sin \left(2 \pi f_{\text {res }} T\right)$ is less than zero. That is, the discretization closed-loop control system will become unstable when formula (19) is satisfied:

$$
\sin \left(\frac{2 \pi f_{\text {res }}}{f_{s}}\right)<0 .
$$

The expression of the unstable region of sampling frequency can be inferred from formula (19), just as formula (10).

Therefore, the research for discretization PI control technology in the above section is demonstrated in theory. The mechanism of the unstable region of sampling frequency can be summarized as follows: due to the discretization of LCL filter, the feedback polarity of closed-loop control will change from negative to positive, which results in unstable control system when the sampling frequency is in unstable region.

\section{Simulation Verification}

In order to verify the theoretical analysis, MATLAB/Simulink software is adopted to the simulation analyses. According to earlier designs, the simulation parameters of LCL filter, $L=$ $1.2 \mathrm{mH}, L_{g}=0.5 \mathrm{mH}, C=8 \mathrm{uF}, R=12 \mathrm{~m} \Omega$, and $R_{g}=5 \mathrm{~m} \Omega$, are elected. The resonant frequency $f_{\text {res }}$ is $3 \mathrm{kHz}$ and the network voltage is $220 \mathrm{~V}$ at $50 \mathrm{~Hz}$. The inverter bridge can be regarded as a controllable voltage source during the simulation.

We can know from formula (10) that when the resonant frequency is $3 \mathrm{kHz}$, the maximum sampling frequency in the unstable region (ribbon) under discrete PI control is $6 \mathrm{kHz}$. Therefore, this paper chooses $10 \mathrm{kHz}$ as the typical value in the stable region and $6 \mathrm{kHz}$ as the typical value in the unstable region. The damping coefficient of closed-loop control system is 0.707 , and the sampling frequency is $10 \mathrm{kHz}$. Figure 8 presents the simulation results when the sampling frequency is $6 \mathrm{kHz}$.

The closed-loop root critical frequency $f_{n \max }$ of stable region is $1647 \mathrm{~Hz}$ when the sampling frequency is $10 \mathrm{kHz}$. In Figures $8(\mathrm{a})-8(\mathrm{c})$, the closed-loop root frequency closes to $1447 \mathrm{~Hz}$ in the time periods $(0,0.1)$ and $(0.2,0.5)$ and to $1747 \mathrm{~Hz}$ in the time period $(0.1,0.2)$. 


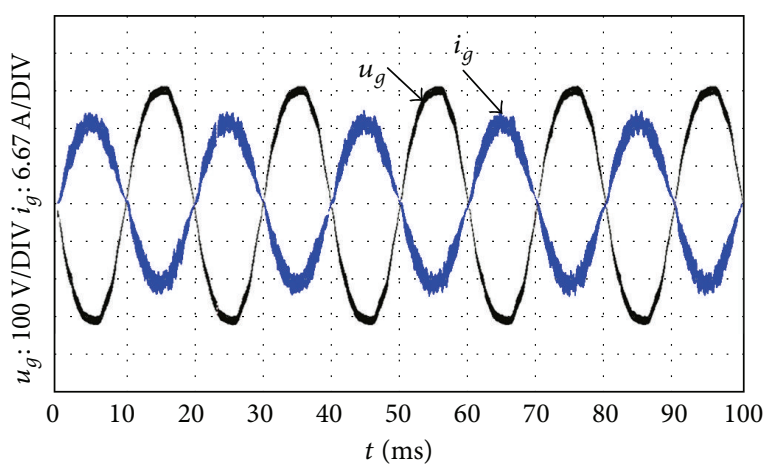

(a) Without filtering

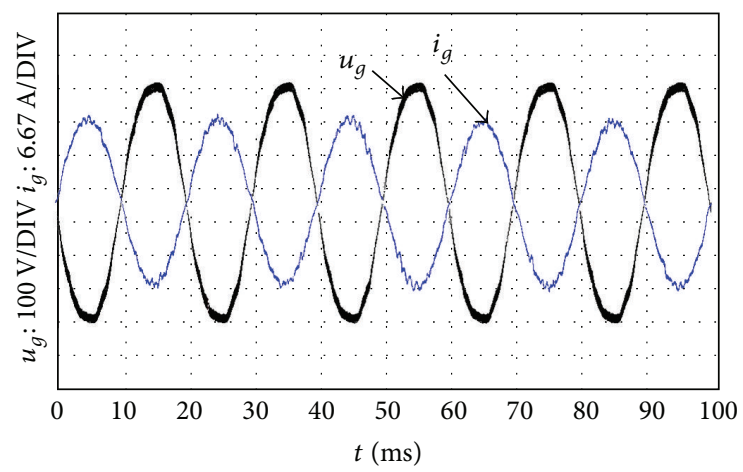

(b) After $5 \mathrm{kHz}$ low-pass filter

FIgURE 9: The experiment waves with $750 \mathrm{~Hz}$.

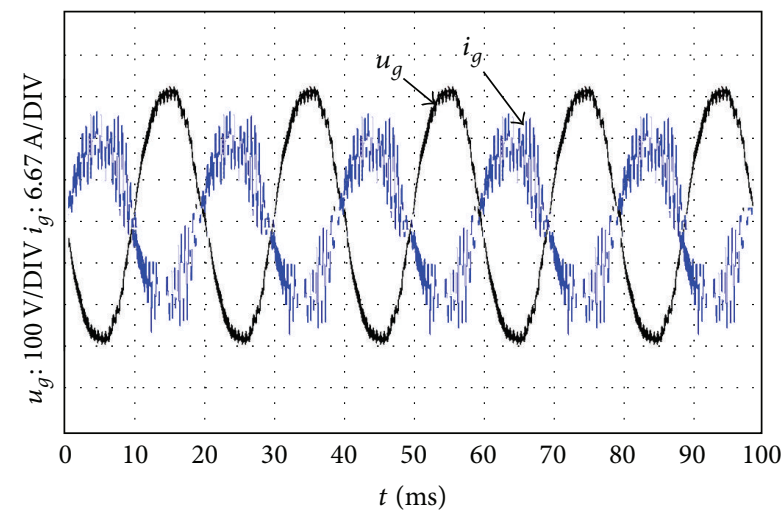

(a) Without filtering

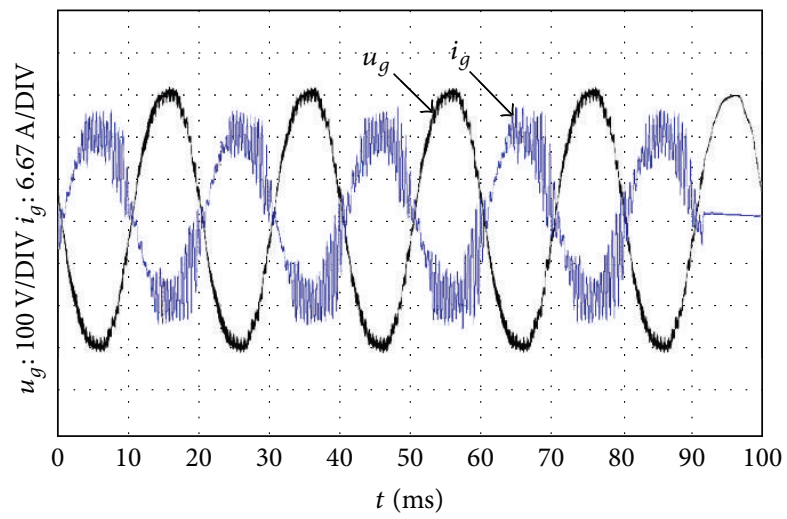

(b) After $5 \mathrm{kHz}$ low-pass filter

FIgURE 10: The experiment waves with $1400 \mathrm{~Hz}$.

Comparing Figure 8(a) with Figure 8(b), the wave in Figure 8(c) has a little distortion resulting from the switching frequency harmonic of PWM.

The steady-state waveform in Figure 8(c) is enlarged as shown in Figure 8(d) from which we can know that there are only harmonics around the switching frequency except for fundamental current in the current wave.

The closed-loop root critical frequency $f_{n \max }$ is $988 \mathrm{~Hz}$ when the sampling frequency is $6 \mathrm{kHz}$. In Figure $8(\mathrm{e})$, the closed-loop root frequency closes to $329 \mathrm{~Hz}$ in the time periods $(0,0.1)$ and $(0.2,0.5)$ and to $1088 \mathrm{~Hz}$ in the time period $(0.1,0.2)$. It can be seen from Figure $8(e)$ that when the sampling frequency is in the unstable region, no matter how much the closed-loop root frequency is, the closed-loop system is unstable, which verifies the theoretical analysis of the unstable region of sampling frequency.

\section{Experimental Verification}

In order to verify the theoretical analysis experimentally, grid-connected photovoltaic inverter $2.5 \mathrm{~kW}$ is selected as a control object. The rated voltage and current of grid are $220 \mathrm{~V}$ at $50 \mathrm{~Hz}$ and $11.4 \mathrm{~A}$, respectively. The inductance is $2 \mathrm{mH}$ and the switching frequency is $10 \mathrm{kHz}$; the sampling frequency is $20 \mathrm{kHz}$ and the closed-loop damping ratio coefficient is 0.707 .
All experiment results are presented in Figures 9 and 10. Each experiment shows two waveforms; the voltage and current waveforms without any filtering are shown in Figure 9(a), while only the current waveform shown in Figure 9(b) is measured with a $5 \mathrm{kHz}$ low-pass filter. Figure 9 shows the voltage and current waveforms when the closed-loop root frequency is $750 \mathrm{~Hz}$ with one-step-delay while Figure 10 shows the results when the closed-loop root frequency is $1400 \mathrm{~Hz}$.

Figures 9 and 10 show that the steady-state characteristic of one-step-delay is good when the closed-loop root frequency is $750 \mathrm{~Hz}$ and the output current has begun to oscillate and enter to the critical stability region when the closed-loop root frequency is $1400 \mathrm{~Hz}$. The stable region of PI control can be considered to coincide with the theoretical calculation when considering the error of inherent parameters of inverter.

The experimental results show that the theoretical derivation of the stable range of digital control parameter (closedloop single frequency) is accurate.

\section{Conclusion}

Since the discrete PI control may cause stability problems, this paper analyzes the range of closed-loop root frequency 
with discrete PI control system to ensure the stability. The following conclusions are obtained: the unstable region of sampling frequency is present in PI control system and the range of closed-loop root frequency will be consistent with discrete PI control of LCL-type filter when the sampling frequency is away from the unstable region. When sampling frequency is in unstable region, the feedback polarity of closed-loop control resulting from the discretization of LCL filter will change from negative to positive, which results in an unstable control system. In practical applications, in order to meet the grid-connected standard indicators, the sampling frequency should be set larger than $9.68 \mathrm{kHz}$ for filters without grid voltage feed forward, but $3.9 \mathrm{kHz}$ for filters with grid voltage feed forward.

\section{Conflict of Interests}

The authors declare that there is no conflict of interests regarding the publication of this paper.

\section{References}

[1] J. Kim, H. Choi, and B. H. Cho, "A novel droop method for converter parallel operation," IEEE Transactions on Power Electronics, vol. 17, no. 1, pp. 25-32, 2002.

[2] K. De Brabandere, B. Bolsens, J. Van den Keybus, A. Woyte, J. Driesen, and R. Belmans, "A voltage and frequency droop control method for parallel inverters," IEEE Transactions on Power Electronics, vol. 22, no. 4, pp. 1107-1115, 2007.

[3] Q. Liu, L. Peng, Y. Kang, S. Tang, D. Wu, and Y. Qi, "A novel design and optimization method of an $L C L$ filter for a shunt active power filter," IEEE Transactions on Industrial Electronics, vol. 61, no. 4, pp. 4000-4010, 2014.

[4] Z. X. Zou, Z. Wang, and M. Cheng, "Modeling, analysis, and design of multifunction grid-interfaced inverters with output LCL filter," IEEE Transactions on Power Electronics, vol. 29, no. 2, pp. 3830-3840, 2014.

[5] Z. Zeng, H. Yang, R. Zhao, and C. Cheng, "Topologies and control strategies of multi-functional grid-connected inverters for power quality enhancement: a comprehensive review," Renewable and Sustainable Energy Reviews, vol. 24, no. 5, pp. 223-270, 2013.

[6] W. Li, X. Ruan, D. Pan, and X. Wang, "Full-feedforward schemes of grid voltages for a three-phase LCL-type grid-connected inverter," IEEE Transactions on Industrial Electronics, vol. 60, no. 6, pp. 2237-2250, 2013.

[7] H. R. Gu, Y. J. Guan, H. B. Wang et al., "Analysis and experimental verification of new power flow control for grid-connected inverter with LCL filter in microgrid," The Scientific World Journal, vol. 2014, Article ID 263590, 8 pages, 2014.

[8] X. Sun, Y. Lee, and D. Xu, "Modeling, analysis, and implementation of parallel multi-inverter systems with instantaneous average-current-sharing scheme," IEEE Transactions on Power Electronics, vol. 18, no. 3, pp. 844-856, 2003.

[9] R. Kabiri, D. G. Holmes, and B. P. McGrath, "Inverter control modeling for distributed generation feeding into a utility network," in Proceedings of the Power Engineering Conference (AUPEC '13), pp. 1-6, Australasian Universities, Hobart, Australia, 2013.

[10] X. Guo, Z. Lu, B. Wang, X. Sun, L. Wang, and J. M. Guerrero, "Dynamic phasors-based modeling and stability analysis of droop-controlled inverters for microgrid applications," The IEEE Transactions on Smart Grid, vol. 99, p. 1, 2014.

[11] X. Zhang, J. W. Spencer, and J. M. Guerrero, "Small-signal modeling of digitally controlled grid-connected inverters with LCL filters," IEEE Transactions on Industrial Electronics, vol. 60, no. 9, pp. 3752-3765, 2013.

[12] C. X. Yang, H. J. Xie, and C. Zhang, "Research on grid-connected inverter based on fuzzy PI controller with self-tuning parameter in wind generation system," in Proceeding of the International Conference on Electric Information and Control Engineering (ICEICE '11), pp. 4403-4406, Wuhan, China, April 2011.

[13] M. Castilla, J. Miret, J. Matas, L. García de Vicuña, and J. M. Guerrero, "Linear current control scheme with series resonant harmonic compensator for single-phase grid-connected photovoltaic inverters," IEEE Transactions on Industrial Electronics, vol. 55, no. 7, pp. 2724-2733, 2008.

[14] M. Liserre, A. Dell'Aquila, and F. Blaabjerg, "Genetic algorithmbased design of the active damping for an LCL-filter three-phase active rectifier," IEEE Transactions on Power Electronics, vol. 19, no. 1, pp. 76-86, 2004.

[15] I. J. Gabe, J. R. Massing, V. F. Montagner, and H. Pinheiro, "Stability analysis of grid-connected voltage source inverters with LCL-filters using partial state feedback," in Proceedings of the European Conference on Power Electronics and Applications (EPE '07), pp. 1-10, Aalborg, Denmark, September 2007.

[16] R. P. Alzola, M. Liserre, and F. Blaabjerg, "Self-commissioning notch filter for active damping in three phase LCL-filter based grid converters," in Proceedings of the 15th European Conference on Power Electronics and Applications, pp. 1-9, Lille, France, 2013.

[17] W. J. Yin and Y. D. Ma, "Research on three-phase PV gridconnected inverter based on LCL filter," in Proceedings of the IEEE 8th Conference on Industrial Electronics and Applications (ICIEA '13), pp. 1279-1283, Melbourne, Australia, June 2013.

[18] H. Heo, W. Im, J. Kim, and J. Kim, "A capacitance estimation of film capacitors in an LCL-filter of grid-connected PWM converters," Journal of Power Electronics, vol. 13, no. 1, pp. 94-103, 2013.

[19] W. M. Wu, Y. J. Sun, and Z. Lin, "A new LC L-filter with in-series parallel resonant circuit for single-phase grid-tied inverter," IEEE Transactions on Industrial Electronics, vol. 61, no. 9, pp. 4640-4644, 2014.

[20] E. Twining and D. G. Holmes, "Grid current regulation of a three-phase voltage source inverter with an LCL input filter," IEEE Transactions on Power Electronics, vol. 18, no. 3, pp. 888895, 2003.

[21] B. Yang, W. Li, Y. Zhao, and X. He, "Design and analysis of a grid-connected photovoltaic power system," IEEE Transactions on Power Electronics, vol. 25, no. 4, pp. 992-1000, 2010.

[22] F. Blaabjerg, R. Teodorescu, M. Liserre, and A. V. Timbus, "Overview of control and grid synchronization for distributed power generation systems," IEEE Transactions on Industrial Electronics, vol. 53, no. 5, pp. 1398-1409, 2006.

[23] N. Abdel-Rahim and J. E. Quaicoe, "Indirect current control scheme for a single-phase voltage-source utility interface inverter," in Proceedings of the Canadian Conference on Electrical and Computer Engineering, vol. 1, pp. 305-308, Vancouver, Canada, September 1993.

[24] M. Y. Xue, Decoupled control and optimized design of grid-connected inverter with LCL filter [Ph.D. thesis], Huazhong University of Science \& Technology, Wuhan, China, 2012. 
[25] M. Yu, Research on key technique of multi-inverter parallel system and grid-on inverter in photovoltaic power generation system [Ph.D. thesis], Huazhong University of Science \& Technology, Wuhan, China, 2009.

[26] C. Y. Hou, X. H. Hu, and D. Hui, "Control strategy of grid-connected converter with LCL filter based on discrete state-space model," Proceedings of the Chinese Society of Electrical Engineering, vol. 31, no. 36, pp. 8-15, 2011. 


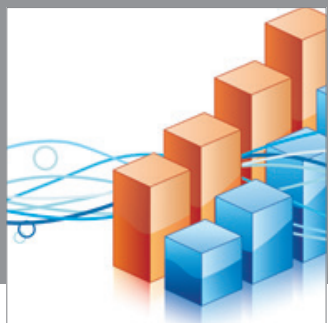

Advances in

Operations Research

mansans

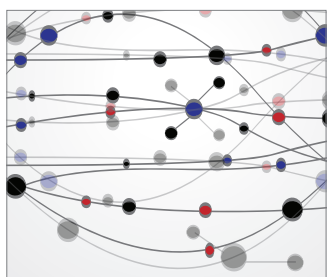

The Scientific World Journal
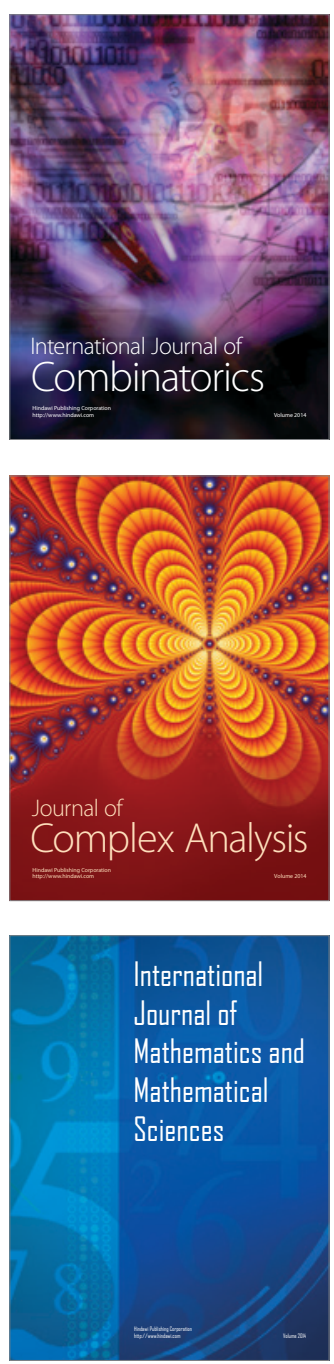
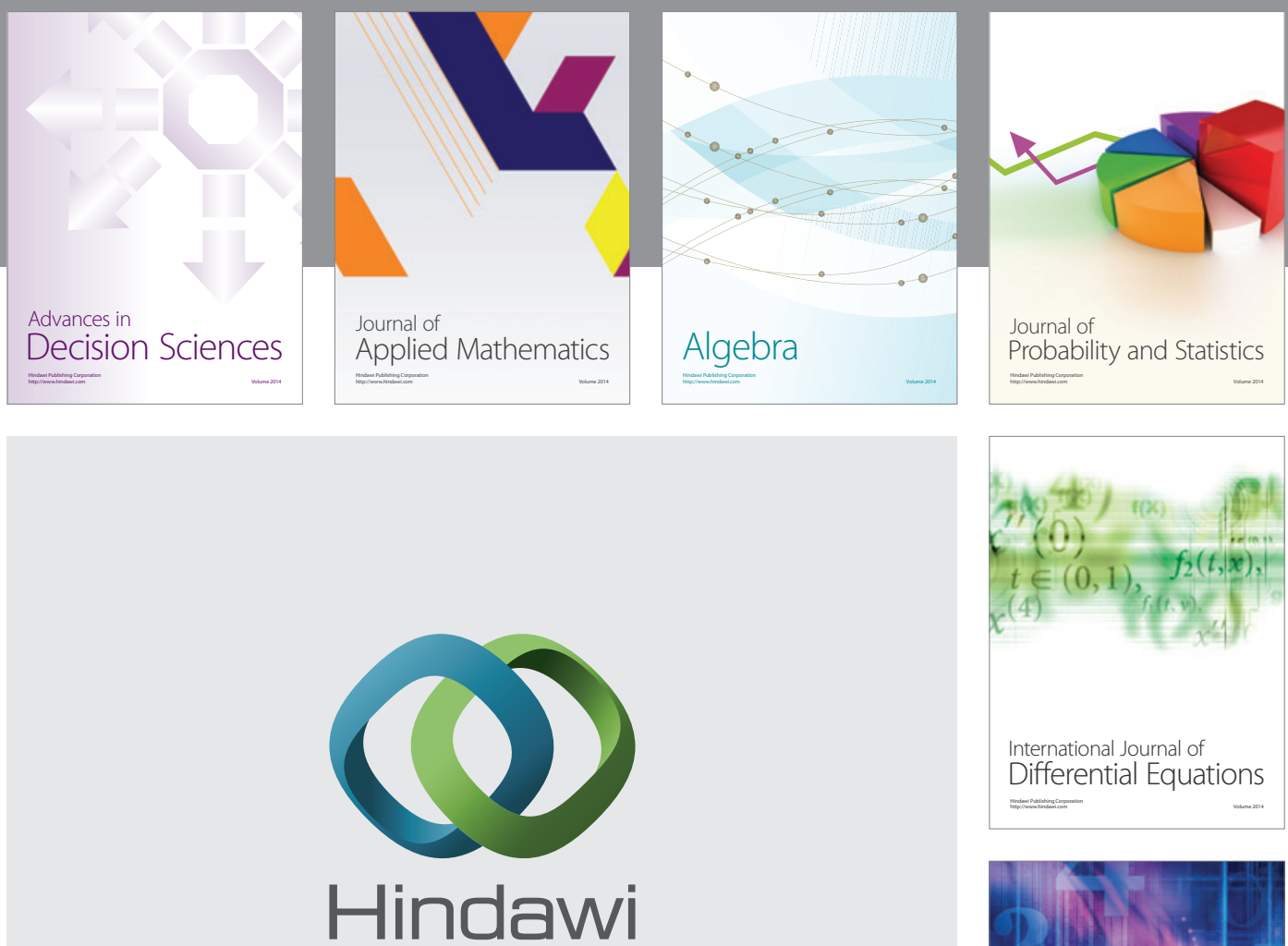

Submit your manuscripts at http://www.hindawi.com
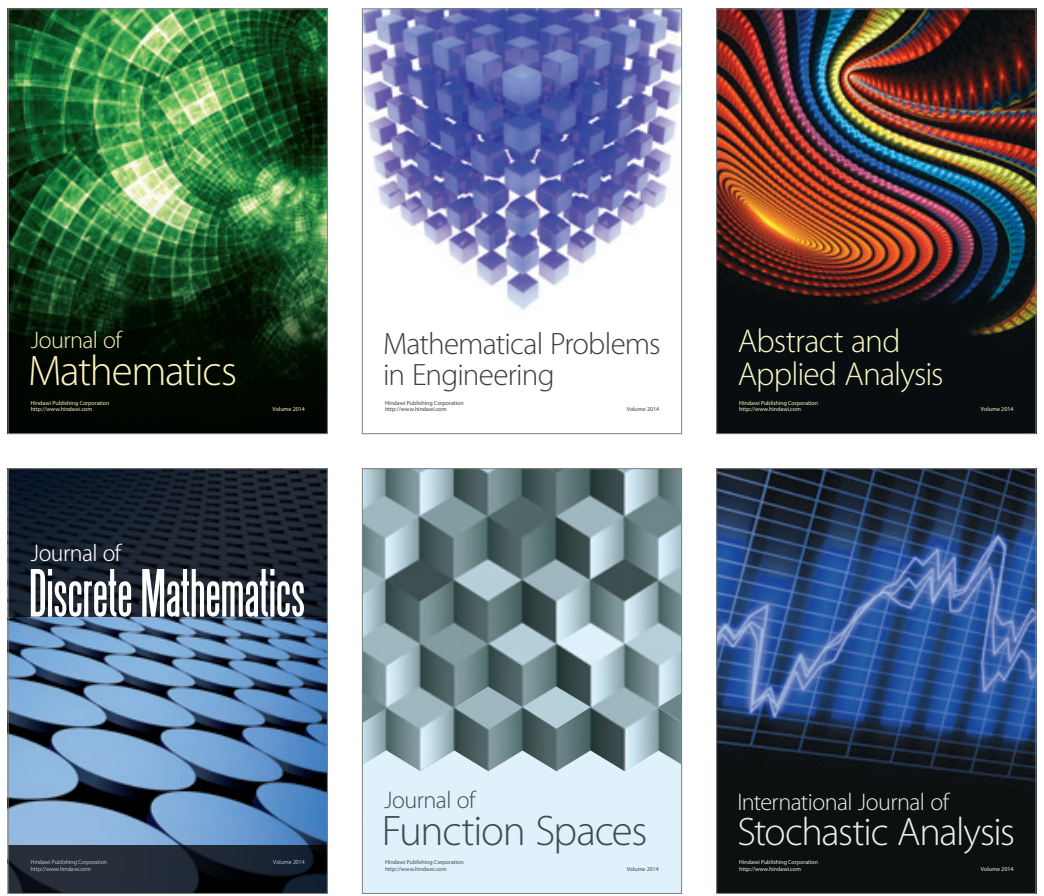

Journal of

Function Spaces

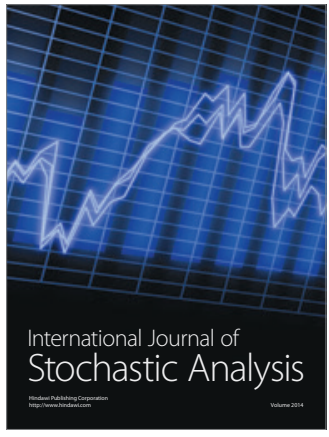

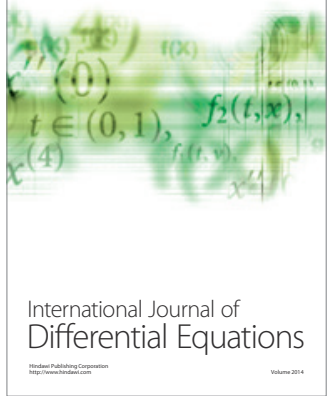
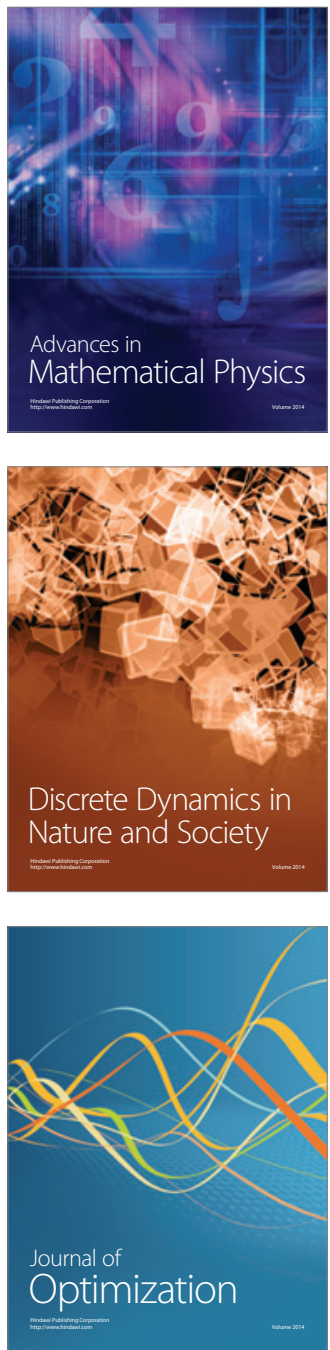